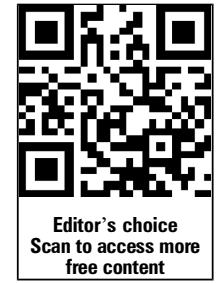

Department of Neurology, Parkinson's Disease Center and Movement Disorders Clinic, Baylor College of Medicine, Houston, Texas, USA

\section{Correspondence to} Dr Joseph Jankovic, Department of Neurology, Parkinson's Disease Center and Movement Disorders Clinic, Baylor College of Medicine, The Smith Tower, Suite 1801, 6550 Fannin, Houston, TX 77030, USA; josephj@bcm.tmc.edu

Received 10 January 2013 Revised 9 June 2013 Accepted 10 September 2013 Published Online First 4 October 2013

\section{SLinked}

http://dx.doi.org/10.1136 jnnp-2013-305271

- http://dx.doi.org/10.1136/ jnnp-2013-305832

To cite: BaizabalCarvallo JF, Kagnoff MN Jimenez-Shahed J, et al. J Neurol Neurosurg Psychiatry 2014;85:567-572.

\title{
The safety and efficacy of thalamic deep brain stimulation in essential tremor: 10 years and beyond
}

\author{
José Fidel Baizabal-Carvallo, Melissa N Kagnoff, Joohi Jimenez-Shahed, \\ Robert Fekete, Joseph Jankovic
}

\section{ABSTRACT \\ Background Deep brain stimulation (DBS) has proven to be a safe and effective therapy for refractory essential tremor, but information regarding long-term outcomes is lacking.}

Objectives We aimed to assess the long-term safety and efficacy of DBS in patients with essential tremor. Methods Patients treated with DBS for essential tremor for at least 8 years were evaluated in the 'on' and 'off' state using the Fahn-Tolosa-Marin tremor rating scale, and their medical records were reviewed to assess complications related to this therapy.

Results We studied 13 patients ( 7 men): median age at evaluation 79 years (range 47-88), median age at electrode implantation 68 years (range $37-78$ ) and mean time since electrode implantation 132.54 \pm 15.3 months (range 114-164). The difference between the 'off' and 'on' state on the motor items of the tremor rating scale was $41.9 \%$ (58.62 vs $34.08, p<0.001)$ in the non-blinded and $37.2 \%$ (56.07 vs $35.23, p<0.001$ ) in the blinded rating. DBS provided a functional improvement of $31.7 \%$ in the 'on' state (15.07 vs 22.07, $\mathrm{p}<0.001)$. A total non-blinded improvement in the tremor rating scale of $39 \%$ was observed in the 'on' state $(49.15$ vs $80.69, \mathrm{p}<0.001)$. Dysarthria and disequilibrium were common in patients with bilateral stimulation. A DBS-related surgery (electrode revision or internal pulse generator exchange) was necessary on average every 47.9 months to continue with the DBS therapy.

Conclusions Thalamic DBS is a safe and effective therapy in patients with essential tremor followed for up to 13 years.

\section{INTRODUCTION}

Essential tremor (ET) is considered one of the most common neurological disorders with a prevalence of $4.6 \%$ in people aged 65 years or older. ${ }^{1}$ Community-based studies have reported at least mild functional impairment in $60 \%$ of patients with ET. $^{2}$ It has been estimated that between 25\% and $55 \%$ of patients have medication-refractory tremor, ${ }^{3}$ resulting in marked morbidity. Deep brain stimulation (DBS) has been documented to provide substantial symptomatic and functional benefit, with a relatively low rate of adverse effects and hardware complications in patients with severe or medication-refractory ET. ${ }^{4}$ However, information regarding safety and efficacy beyond 8 years following implantation is unavailable. ${ }^{6-9}$ We aimed to describe the long-term outcomes of DBS for patients followed for about a decade after the initial electrode implantation surgery.

\section{PATIENTS AND METHODS}

Patients implanted unilaterally or bilaterally in the ventral intermediate (Vim) nucleus of the thalamus for treatment of disabling or medication-refractory ET for at least 8 years were identified from a database at the Parkinson's Disease Center and Movement Disorders Clinic, Baylor College of Medicine. The patients were contacted and invited to participate in the study.

Inclusion criteria required all patients to have a diagnosis of ET made by a movement disorders specialist and be treated continuously with unilateral or bilateral Vim DBS for at least 8 years, with interruption periods no longer than 3 months since the implantation surgery. Patients with other comorbid neurological or movement disorders (ie, Parkinson's disease) were excluded from the study. The effect of DBS on tremor amplitude and functional impact was assessed with the Fahn-TolosaMarin (FTM) tremor rating scale. ${ }^{10}$ The scale includes evaluation of tremor (items 1-9), hand function (items 10-14) and activities of daily living (ADL) (items 15-21).

The primary outcome of the study was the difference in the FTM tremor rating scale total scores during the DBS 'off' and 'on' states carried out by two independent movement disorders specialists in a blinded and non-blinded fashion. Additionally, individual subscores of the different FTM tremor scale's items were compared. Secondary outcomes included side effects of the stimulation, hardware and perioperative complications, number of battery replacements and changes in the stimulation setting during the total period of stimulation.

During the study visit, all patients were initially assessed with the DBS 'on' using the FTM scale. DBS settings were then optimised in order to provide the best possible efficacy in contralateral tremor amplitude, while avoiding or minimising side effects related to the stimulation. A second assessment using the FTM rating scale was then carried out and patients were videotaped in the 'on' state. Finally, the DBS was turned off for $15 \mathrm{~min}$ and a second evaluation and video recordings were carried out. The video recordings followed a standardised protocol sequence that permitted the assessment of items 1-14 of the FTM scale. The videos were sent to an external movement disorders specialist (RF), who was blinded to the stimulation status ('on' or 'off') and 
reviewed and rated all videos. The blinded video rater also classified patients as being in the 'on' or 'off' DBS state. Unwanted side effects of DBS, such as speech and gait abnormalities, were recorded during the non-blinded evaluations. As the blinded evaluation of video recordings has the potential disadvantage of missing subtle tremors, both blinded and non-blinded evaluations are reported in this study. Patients were asked to stop their medications for ET $12 \mathrm{~h}$ before the study visit.

To establish whether patients had an initial good response to DBS therapy, a retrospective chart review was carried out to evaluate the overall effect of DBS on tremor 1-2 months following implantation surgery. This time was chosen to avoid overestimation related to microlesion effect of electrode implantation. Patients were classified as follows: (1) no improvement, (2) less than 25\% improvement, (3) 25\%-50\% improvement, (4) 50\%$75 \%$ improvement, (5) $\geq 75 \%$ improvement and (6) complete or nearly complete $(>90 \%)$ tremor resolution-a similar strategy has been used in a previous study. ${ }^{11}$ The stimulators were usually turned on 2-3 weeks after the implantation surgery. During the first 5-6 weeks, the stimulation parameters were adjusted to get optimal control of tremor without side effects. All patients were implanted with equipment from Medtronic, Inc (Minneapolis, Minnesota, USA) and stimulated with constant voltage. The surgical technique carried out in all patients has been described elsewhere. ${ }^{12}$ All patients underwent a postoperative brain MRI, which confirmed the position of the implanted electrodes into the Vim.

The number of internal pulse generator (IPG) exchanges, operative and hardware complications was recorded. We assessed the mean frequency in months of DBS-related surgeries (IPG exchanges and electrode revisions). Changes in the stimulation settings, including current amplitude (volts), pulse width $(\mu s)$ and frequency (Hertz), were assessed comparing the settings used following the first DBS programming session and the last DBS settings following optimisation during the study visit. The study was approved by the local IRB of Baylor College of Medicine, and all patients signed written informed consent to participate in the study.

\section{Statistical analysis}

Data were summarised in medians, means \pm SDs, range and frequencies in percentages. The Wilcoxon signed-rank test was used to compare the total and subtotal scores values of the FTM tremor rating scale in the 'off' and 'on' DBS state. All statistical evaluations were performed using SPSS V.13, and a $\mathrm{p}$ value $<0.05$ was considered statistically significant.

\section{RESULTS}

A total of 48 patients were identified from our database as implanted before the year 2003. From this cohort, 17 patients were lost to follow-up ( 9 patients were from another state outside of Texas), 13 patients were deceased at the time of the study inclusion (none of them related to a DBS complication), 2 patients were later assigned with another diagnosis (one with Parkinson's disease and one with multiple system atrophy), 1 patient had the DBS turned off for several years due to lack of clinical benefit and 2 patients declined to participate in the study.

A total of 13 patients ( 7 men) were enrolled in the study and completed all the assessments. The median age at inclusion was 79 years (range 47-88), the median age at first electrode implantation was 68 years (range $37-78$ ) and the mean time since electrode implantation was 132.54 \pm 15.3 months (range 114-164). Seven patients had bilateral Vim DBS; five patients had unilateral left Vim DBS and one had unilateral right Vim DBS (table 1).

Table 1 Clinical and demographic features of patients from this series

\begin{tabular}{|c|c|c|c|c|c|c|c|c|c|}
\hline Case & Gender & $\begin{array}{l}\text { Age at } \\
\text { evaluation } \\
\text { (years) }\end{array}$ & $\begin{array}{l}\text { Target } \\
\text { nucleus } \\
\text { (VIM) }\end{array}$ & $\begin{array}{l}\text { Age at surgical } \\
\text { implantation } \\
\text { (years) }\end{array}$ & $\begin{array}{l}\text { Time with } \\
\text { DBS }\end{array}$ & $\begin{array}{l}\text { Initial tremor } \\
\text { improvement } \\
(\%)\end{array}$ & $\begin{array}{l}\text { Number of IPG } \\
\text { replacements }\end{array}$ & $\begin{array}{l}\text { Operatory } \\
\text { complications and } \\
\text { electrode revisions }\end{array}$ & $\begin{array}{l}\text { Side effects of } \\
\text { stimulation }\end{array}$ \\
\hline 1 & $\mathrm{~F}$ & 82 & Bilateral & 73 & $\begin{array}{l}9 \text { years, } \\
6 \text { months }\end{array}$ & $>75$ & 2 & None & $\begin{array}{l}\text { Mild gait ataxia } \\
\text { and dysarthria }\end{array}$ \\
\hline 2 & $M$ & 80 & Left & 68 & $\begin{array}{l}11 \text { years, } \\
10 \text { months }\end{array}$ & $50-75$ & 2 & None & None \\
\hline 3 & $M$ & 78 & Left & 66 & 12 years & $50-75$ & 1 & None & None \\
\hline 4 & $\mathrm{~F}$ & 85 & Bilateral & 72 & 13 years & $50-75$ & 4 & $\begin{array}{l}\text { Vasovagal reaction } \\
\text { during surgery }\end{array}$ & $\begin{array}{l}\text { Mild to } \\
\text { moderate } \\
\text { dysarthria }\end{array}$ \\
\hline 5 & M & 69 & Bilateral & 58 & $\begin{array}{l}11 \text { years, } \\
3 \text { months }\end{array}$ & $>90$ & 3 & None & Mild gait ataxia \\
\hline 6 & $\mathrm{~F}$ & 72 & Left & 61 & $\begin{array}{l}10 \text { years, } \\
9 \text { months }\end{array}$ & $>75$ & 2 & None & None \\
\hline 7 & $M$ & 75 & Bilateral & 64 & $\begin{array}{l}10 \text { years, } \\
8 \text { months }\end{array}$ & $50-75$ & 2 & $\begin{array}{l}\text { Electrode migration } \\
\text { (meningioma) }\end{array}$ & $\begin{array}{l}\text { Mild gait ataxia } \\
\text { and dysarthria }\end{array}$ \\
\hline 8 & $\mathrm{~F}$ & 79 & Bilateral & 65 & $\begin{array}{l}13 \text { years, } \\
8 \text { months }\end{array}$ & $>90$ & 3 & $\begin{array}{l}\text { Electrode migration } \\
\text { (Unknown cause) }\end{array}$ & $\begin{array}{l}\text { Mild gait ataxia } \\
\text { and dysarthria }\end{array}$ \\
\hline 9 & M & 88 & Bilateral & 78 & $\begin{array}{l}10 \text { years, } \\
3 \text { months }\end{array}$ & $50-75$ & 2 & None & Mild gait ataxia \\
\hline 10 & $\mathrm{~F}$ & 47 & Right & 37 & $\begin{array}{l}10 \text { years, } \\
2 \text { months }\end{array}$ & $>75$ & 3 & None & None \\
\hline 11 & $F$ & 79 & Left & 68 & $\begin{array}{l}10 \text { years, } \\
11 \text { months }\end{array}$ & $50-75$ & 3 & None & Mild dysarthria \\
\hline 12 & M & 85 & Left & 76 & $\begin{array}{l}9 \text { years, } \\
6 \text { months }\end{array}$ & $>90$ & 2 & None & $\begin{array}{l}\text { Mild gait ataxia } \\
\text { and dysarthria }\end{array}$ \\
\hline 13 & $M$ & 80 & Bilateral & 75 & 10 years & $50-75$ & 4 & $\begin{array}{l}\text { Electrode migration } \\
\text { (Unknown cause) }\end{array}$ & Mild gait ataxia \\
\hline
\end{tabular}

DBS, deep brain stimulation; IPG, internal pulse generator replacement; VIM, ventral intermediate. 
Table 2 FTM tremor rating scale, clinical scores in the on and off states

\begin{tabular}{|c|c|c|c|c|c|c|c|}
\hline FTM scale, item & $\begin{array}{l}\text { Maximal } \\
\text { possible score }\end{array}$ & $\begin{array}{l}\text { Non-blinded } \\
\text { DBS 'off' }\end{array}$ & $\begin{array}{l}\text { Non-blinded } \\
\text { DBS 'on' }\end{array}$ & $\begin{array}{l}\text { Blinded } \\
\text { DBS 'off' }\end{array}$ & $\begin{array}{l}\text { Blinded } \\
\text { DBS 'on' }\end{array}$ & p Value* & p Valuet \\
\hline Sum ETRS (1-14) & 116 & 58.62 & 34.08 & 56.07 & 35.23 & $<0.001$ & $<0.001$ \\
\hline Tremor scores (1-9) & 80 & 29.62 & 12.85 & 28.2 & 14.85 & 0.001 & 0.002 \\
\hline Voice tremor & 4 & 1.38 & 0.77 & 2.08 & 2.15 & 0.001 & 0.673 \\
\hline Head tremor $\ddagger$ & 8 & 1.23 & 0.38 & 1.38 & 0.69 & 0.011 & 0.013 \\
\hline \multicolumn{8}{|l|}{ Tremor upper extremity§ } \\
\hline Ipsilateral & 12 & 7.5 & 5.33 & 6.33 & 5.5 & 0.077 & 0.197 \\
\hline Contralateral & 12 & 8.7 & 3.55 & 8.7 & 4.0 & $<0.001$ & $<0.001$ \\
\hline \multicolumn{8}{|l|}{ RUE (item 5) } \\
\hline Rest & 4 & 2.15 & 0.08 & 2.15 & 0.23 & $<0.001$ & 0.001 \\
\hline Postural & 4 & 2.77 & 0.92 & 2.85 & 1.15 & $<0.001$ & 0.002 \\
\hline Action & 4 & 2.77 & 1.54 & 2.77 & 1.62 & 0.001 & 0.002 \\
\hline Handwriting (item 10) & 4 & 2.69 & 1.46 & 2.23 & 1.31 & 0.002 & 0.002 \\
\hline \multicolumn{8}{|c|}{ Hand function (items 11-14) } \\
\hline Ipsilateral & 16 & 11.67 & 11.0 & 10.67 & 9.83 & 0.102 & 0.102 \\
\hline Contralateral & 16 & 13.55 & 9.55 & 13.75 & 9.45 & $<0.001$ & 0.001 \\
\hline $\begin{array}{l}\text { *Comparison between } \\
\text { †Comparison between } \\
\text { łIncludes rest and post } \\
\text { §Includes, rest postural } \\
\text { DBS, deep brain stimul }\end{array}$ & $\begin{array}{l}\text { ded DBS on/off. } \\
\text { on/off DBS. } \\
\text { nor. } \\
\text { ion tremor. Contr }\end{array}$ & bodi & es $n$ & 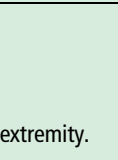 & & & \\
\hline
\end{tabular}

Two patients were taking medication for tremor at the time of the last assessment: case 2 (propranolol $120 \mathrm{mg} /$ day and primidone $250 \mathrm{mg} /$ day) and case 6 (topiramate $50 \mathrm{mg} /$ day and primidone $125 \mathrm{mg}$ tid); both had unilateral DBS and used medication to control ipsilateral tremor.

After initial DBS adjustment, the motor scores of the FTM tremor rating scale (non-blinded) improved 15.12\% (40.15 vs $34.08, p=0.002$ ). Following adjustment of DBS settings, the difference between the 'off' and 'on' state was $41.9 \%$ in the nonblinded evaluation (58.62 vs $34.08, \mathrm{p}<0.001$; table 2 ). The blinded evaluator 'guessed' correctly in all patients whether the patient was in the DBS 'on' or 'off' state. The blinded evaluation yielded a difference between the 'off' and 'on' DBS state of $37.2 \%$ (56.07 vs $35.23, \mathrm{p}<0.001)$. Statistically significant differences in blinded and unblinded assessments were observed mainly in the items evaluating head and contralateral upper limb tremor, as well as handwriting, drawing spirals and water pouring. The FTM tremor rating scale items 1-9 (tremor) improved $47.5 \%$ (28.2 vs $14.85, \mathrm{p}=0.02)$ in the blinded evaluation with the DBS 'on', whereas items 10-14 (hand writing and hand function) improved $27 \%$ (27.8 vs $20.3, \mathrm{p}=0.02$ ). When considering only the contralateral right upper limb tremor items (rest, postural and kinetic), an improvement of $54 \%$ was observed in the DBS 'on' state $(8.7$ vs $4.0, \mathrm{p}<0.001)$ according to the blinded evaluation. Improvement in ipsilateral tremor in patients with unilateral DBS was also observed in the blinded and non-blinded evaluations (table 2).

DBS provided a $31.72 \%$ improvement in the ADL items of the FTM rating scale in the 'on' state $(22.07$ vs 15.07 , $\mathrm{p}<0.001)$. All items showed a statistically significant improvement except for item 15: 'speaking' (table 3). All patients in this study preferred the DBS 'on' state rather than the 'off' state despite persistent impairments as rated on the clinical and functional scores with the DBS turned on.

An initial overall improvement in tremor of at least 50\% was observed in all our patients following surgery, with almost complete resolution of contralateral tremor in three $(23 \%)$ patients (table 1). In this series, patients had a mean of 2.54 IPG exchange surgeries (range 1-4) during the total follow-up period. One patient suffered a vasovagal reaction with hypotension and loss of consciousness during the implantation surgery; the electrodes were implanted 3 months later without complications. Hardware complications were observed in three $(23 \%)$ patients during the follow-up period. One patient had an electrode migration secondary to external compression by a midline meningioma. He regained tremor control after removal of the tumour; this case was reported in detail elsewhere. ${ }^{13}$ Two patients had electrode migrations of unknown cause; both patients required surgical revision of the migrated electrode resulting in marked tremor improvement. After the initial electrode implantation, a total of 36 DBS-related surgeries were carried out in our patients; on average, participants had one surgery every 47.9 months.

Table 3 FTM tremor rating scale, functional scores in the 'on' and 'off' states

\begin{tabular}{|c|c|c|c|c|}
\hline FTM scale, item & $\begin{array}{l}\text { Baseline } \\
\text { evaluation } \\
\text { DBS 'off' }\end{array}$ & $\begin{array}{l}\text { Baseline } \\
\text { evaluation } \\
\text { DBS 'on' }\end{array}$ & $\begin{array}{l}\text { Mean } \\
\text { improvement } \\
(\%)\end{array}$ & $\begin{array}{l}p \\
\text { Value }\end{array}$ \\
\hline 15. Speaking & 1.92 & 1.69 & 11.92 & 0.190 \\
\hline $\begin{array}{l}\text { 16. Feeding other than } \\
\text { liquids }\end{array}$ & 3.15 & 2.15 & 31.75 & 0.004 \\
\hline $\begin{array}{l}\text { 17. Bringing liquids to } \\
\text { mouth }\end{array}$ & 3.54 & 2.54 & 28.25 & 0.009 \\
\hline 18. Hygiene tasks & 3.46 & 2.15 & 37.86 & $<0.001$ \\
\hline 19. Dressing & 3.23 & 2.08 & 35.61 & $<0.001$ \\
\hline 20. Writing & 3.31 & 2.08 & 37.17 & 0.001 \\
\hline 21. Working tasks & 3.46 & 2.38 & 31.22 & 0.001 \\
\hline ADL score (total) & 22.07 & 15.07 & 31.72 & $<0.001$ \\
\hline Total score & 80.69 & 49.15 & 39.09 & $<0.001$ \\
\hline
\end{tabular}

FTM scale functional scores range from $0=$ normal, $1=$ mildly abnormal, $2=$ moderately abnormal, $3=$ markedly abnormal and $4=$ severely abnormal.

$\mathrm{ADL}$, activities of daily living; DBS, deep brain stimulation; FTM, Fahn-Tolosa-Marin. 
Table 4 DBS configuration and settings

\begin{tabular}{llll}
\hline & Baseline $^{*}$ & Last adjustment & p Value \\
\hline Monopolar/bipolar & $4 / 16$ & $9 / 11$ & - \\
Amplitude $(V)$ & $3.05 \pm 0.50(1.50-4.00)$ & $3,25 \pm 0.81(1.50-4.60)$ & 0.256 \\
Pulse width ( $\mu \mathrm{s})$ & $109.25 \pm 46.9(60-210)$ & $114.0 \pm 41.9(60-210)$ & 0.676 \\
Frequency (Hz) & $149 \pm 30.5(90-185)$ & $161.7 \pm 23.9(100-185)$ & 0.140 \\
\hline
\end{tabular}

Numbers are means and SD (range).

${ }^{*}$ At 5-6 weeks after surgery.

DBS, deep brain stimulation.

During the follow-up period, 12 out of 13 patients experienced tremor deterioration requiring higher DBS settings (table 4). Adverse effects were relatively infrequent, but six out of seven patients $(86 \%)$ with bilateral DBS had mild gait ataxia with the optimal levels of stimulation to control tremor; gait was not evaluated in one patient with bilateral DBS as she was wheelchair-bound secondary to orthopaedic problems. One out of six patients with unilateral DBS showed mild gait ataxia. Mild dysarthria was observed in four $(57 \%)$ patients with bilateral and in two (33\%) patients with unilateral DBS (table 1).

\section{DISCUSSION}

In this study, the safety and efficacy of Vim DBS in 13 patients with severe, medication-refractory ET were assessed 8-13 years after initial electrode implantation. An improvement of $41.9 \%$ $(p<0.001)$ in the FTM total score was observed in the nonblinded evaluation and $37.2 \%(p<0.001)$ in the blinded evaluation. The difference between the blinded and non-blinded evaluations was observed predominantly in the items evaluating axial tremor, such as facial, voice and trunk tremor. These differences could be explained by difficulties perceiving axial tremor on the video recordings, but could also represent a sort of bias in the non-blinded evaluator due to overestimation of the stimulation effect. The most evident difference between blinded and non-blinded evaluation was observed in the assessment of voice tremor, which could be related to difficulties to appreciate the tremor in the audio recordings. Items assessing contralateral upper limb tremor were significantly different in the 'on' and 'off' DBS state, regardless of the type of evaluation carried out (blinded or non-blinded).

In a review of nine studies of patients with unilateral or bilateral Vim DBS for ET, an improvement of 33\%-82\% in tremor amplitude was observed. ${ }^{14}$ There are few studies assessing the long-term ( $>5$ years) effects of DBS on ET (table 5 ). In two studies that followed patients for 6.5 years (78 months), an overall tremor improvement of $43 \%$ was observed ${ }^{6} 7$, which is slightly higher than our findings. Another study reported a 60.3\% improvement in hand tremor in 19 patients followed for 86 months. ${ }^{15}$ This is similar to the $54 \%$ improvement in contralateral tremor observed in our study with the blinded assessment.

DBS for ET has proven to be an effective therapy for improving several scales related to ADL and quality of life. ${ }^{16}{ }^{17}$ In our series, scores related to ADL improved $31.72 \%$ with the stimulation therapy. This figure is lower than the 51\% improvement in ADL observed at 6 years in a study of 19 patients with ET treated with thalamic $\mathrm{DBS}^{6}$ but similar to the one found by Blomstedt et $a l^{15}(32.3 \%)$ in 19 patients followed for 86 months. These differences could be the result of a longer follow-up period and/or lack of statistical improvement in item 15: (speaking) observed in our study.

Gradual loss of tremor control over months or years occurs in some patients with ET treated with DBS. Several explanations have been proposed regarding this phenomenon, including development of tolerance to stimulation, misdiagnosis and

Table 5 Case series of patients with essential tremor with a mean follow-up period of at least 5 years

\begin{tabular}{|c|c|c|c|c|}
\hline $\begin{array}{l}\text { Author (year of } \\
\text { publication) }\end{array}$ & $\begin{array}{l}\text { Number of } \\
\text { patients }\end{array}$ & $\begin{array}{l}\text { Average follow-up } \\
\text { period }\end{array}$ & Clinical (\%) improvement DBS off vs on state* & Complications \\
\hline Rehncrona et al (2003) & 13 total & $6.5 \pm 0.3$ years & $\begin{array}{l}\text { ETRS (total): }(43 \%) p<0.025 \text {. } \\
\text { Hand function: }(56 \%)\end{array}$ & NR \\
\hline Sydow et al (2003) & $\begin{array}{l}19 \text { total } \\
12 \text { unilateral } \\
7 \text { bilateral }\end{array}$ & $6.53 \pm 0.6$ years & $\begin{array}{l}\text { Tremor items: } 19.4 \text { vs } 10.4,(46.4 \%) \text {. } \\
\text { Hand function items: } 25.6 \text { vs } 16.4,(36 \%) \text {. } \\
\text { ADL items: } 17.4 \text { vs } 8.4,(51.7 \%) \text {. } \\
\text { All subscores: } p<0.001 . \\
\text { Overall improvement: } 43 \%\end{array}$ & $\begin{array}{l}\text { Total postoperative adverse } \\
\text { events: } 40 \text {. Dysarthria was more } \\
\text { common with bilateral } \\
\text { stimulation }\end{array}$ \\
\hline Pahwa et al (2006) & $\begin{array}{l}22 \text { total } \\
15 \text { unilateral } \\
7 \text { bilateral }\end{array}$ & 5 years & $\begin{array}{l}\text { Tremor scores: } \\
\text { Unilateral: } 21.7 \text { vs } 11.7,(46 \%) p<0.01 \text {. } \\
\text { Bilateral: } 21.3 \text { vs } 6.4,(70 \%) p=0.02 \\
\text { ADL items: }(36-51 \%)\end{array}$ & $\begin{array}{l}\text { Dysarthria, balance difficulties, } \\
\text { dysphagia, salivation were more } \\
\text { common with bilateral thalamic } \\
\text { stimulation }\end{array}$ \\
\hline Blomstedt et al (2007) & $\begin{array}{l}19 \text { total (All } \\
\text { unilateral) }\end{array}$ & $86 \pm 9$ months & $\begin{array}{l}\text { Tremor items: } 19.3 \text { vs } 11.7,(39.3 \%) \text {. } \\
\text { Hand function items: } 25.6 \text { vs } 20.6,(19.5 \%) \text {. } \\
\text { ADL, items: } 20.1 \text { vs } 13.6,(32.3 \%) \\
\text { Total: } 68.1 \text { vs } 47.4,(30.4 \%) \\
\text { All subscores: } p \leq 0.01\end{array}$ & 6 patients had a broken wire \\
\hline Zhang et al (2010) & 12 total & 90.7 months & $\begin{array}{l}\text { Tremor: } 3.33 \text { vs } 0.67,(79.8 \%) \\
\text { Handwriting: } 2.80 \text { vs } 1.30,(53.5 \%)\end{array}$ & $\begin{array}{l}\text { Overall hardware complications: } \\
23.5 \%\end{array}$ \\
\hline Present series & $\begin{array}{l}13 \text { total } \\
7 \text { bilateral } \\
6 \text { unilateral }\end{array}$ & $132.54 \pm 15.3$ months & $\begin{array}{l}\text { Tremor items (blinded): } 28.2 \text { vs } 14.85(47.5 \%) \text {, } \\
p=0.02 \text {. } \\
\text { Hand function items (blinded)t: } 27.8 \text { vs } 20.3,(27 \%) \text {, } \\
p=0.02 \text {. } \\
\text { ADL items: }(31.7 \%), p<0.001 \text {. } \\
\text { Total: } 80.6 \text { vs } 49.1(39 \%), p<0.001\end{array}$ & $\begin{array}{l}\text { Hardware complications: } 23 \% \text {. } \\
\text { Dysarthria and ataxia were more } \\
\text { common with bilateral } \\
\text { stimulation }\end{array}$ \\
\hline
\end{tabular}

*Fahn-Tolosa-Marin tremor rating scale, including tremor items 1-9, hand function items 10-14 and ADL items 15-21.

tIncluding handwriting (item 10).

ADL, activities of daily living; DBS, deep brain stimulation; ETRS, Essential Tremor Rating Scale. 
disease progression. ${ }^{14} 15$ In our series, most patients had prominent clinical and functional improvement according to the retrospective evaluation of individual cases. The evaluation in the 'off' DBS state showed high scores (56.07-58.6), which, along with progressively higher stimulation settings and perception of functional decline in 12 out of 13 patients, suggests tremor progression. However, despite tremor progression, patients perceived a substantial benefit from DBS in our longterm study, although some patients required slightly higher stimulation settings to achieve tremor control. A study of 28 ET patients treated with Vim DBS demonstrated tremor progression in seven (25\%) patients and a $34 \%$ increase in tremor score with the DBS 'off' at 36 months compared with $32 \%$ increase among controls $(\mathrm{p}=0.67) .{ }^{18}$ Despite tremor progression, most authors have reported relatively minor increases in stimulation settings in ET patients followed for 5 years and beyond, ${ }^{7-9}$ similar to our findings.

Several studies have demonstrated that DBS is a safe treatment for ET. ${ }^{4}$ In the present study, hardware complications occurred in three $(23 \%)$ patients. This is similar to the percentage reported by Zhang et $a l^{8}(23.5 \%)$. All our cases with hardware complications had electrode migrations, and no lead fractures or infections were observed. Hardware complications occurred in $8.7 \%$ in a large series of patients with movement disorders and seem to be more common in those with $\mathrm{ET}^{13}$ In the present cohort, a DBS-related surgery (IPG exchange surgery or electrode revision) was necessary on average every 47.9 months in order to continue with the therapy. The relative short longevity of the IPGs in our patients was likely related to chronic continuous stimulation and relatively high stimulation settings (ie, high pulse width) used; whether this led to tolerance to stimulation is a possibility that has been hypothesised but not definitely proven.

A foreign body such as an electrode used for DBS implanted in the brain is usually well tolerated in the long term. Autopsy studies have demonstrated minimal pathological changes around the electrodes 16 months and 12 years after the implantation surgery, with minimal foreign body reaction, gliosis and lymphocyte infiltration. ${ }^{19} 20$

In our series, balance disturbances and dysarthria occurred in most patients with bilateral DBS and were less frequently observed with unilateral DBS. An improvement in the DBS 'off' state was observed in all of these cases. This is consistent with another study in which dysarthria and balance difficulties were observed in $75 \%$ and $56 \%$ of patients, respectively, with tremor treated with thalamic bilateral Vim stimulation followed for 5 years. ${ }^{9}$ Mild DBS-induced dysarthria could be the reason why no difference was observed in the item 'speaking' of the FTM scale in our study. Although this item aims to assess only voice tremor and spastic dysphonia, patients may have difficulties to discriminate them from dysarthria. Despite the presence of dysarthria and gait imbalance, all patients preferred these side effects rather than lower stimulation parameters, resulting in higher tremor amplitude and tremor-related disability. Other side effects such as transient and persistent paresthesias, pain and stimulation-induced dystonia were commonly observed during the programming sessions in all patients; however, settings were optimised to avoid these side effects.

There are several limitations to our study, including the relatively small sample size due to a high number of patients lost at follow-up. This is partially due to the fact that our referral centre provides care for patients with movement disorders within a vast geographic area. Also, several patients were implanted at a relatively advanced age, which increased the probability of loss at follow-up due to death or institutionalisation. Despite these limitations, however, we were able to demonstrate a robust effect in the DBS 'on' state in all but one patient with the FTM rating scale using blinded video-recording evaluations. Despite the lack of objective evaluations at baseline and postoperative state, all patients had marked improvement in tremor within the first 1-2 months after implantation surgery. Another potential limitation is the relatively short washout time (15 min) between the 'off' and 'on' state, which may have underestimated the benefit provided by the DBS. However, there is a possibility that this short washout period may have in fact overestimated the effect of DBS due to a rebound effect observed in the first minutes after the DBS is turned off. How this short time affected the degree of benefit observed in our study is not clear, but it was chosen to protect patients as most of them experienced severe tremor and discomfort when the DBS was turned off.

Our study explores exclusively the long-term effects of Vim stimulation. Other studies have evaluated the long-term effects of the caudal zona incerta $(\mathrm{cZi})$ as an alternative target to Vim for $\mathrm{ET}^{21}$ In a study of 19 patients followed for 48.5 \pm 10.6 months, an improvement of $52 \%$ in the 'on' state was noticed in tremor scores of the Essential Tremor Rating Scale (ETRS), with a 78\% improvement in hand function and $68 \%$ in ADL, and a relatively low rate of side effects. ${ }^{22}$ These data suggest that the $\mathrm{cZi}$ can also provide a sustained positive effect for the treatment of ET. It has been reported that $\mathrm{cZi}$ stimulation is related to a lower rate of dysarthria, disequilibrium and less tolerance than Vim stimulation ${ }^{21}{ }^{22}$; however, head-to-head comparisons of both targets are lacking.

In conclusion, Vim DBS can provide a sustained and marked benefit in tremor control and ADL scores even 13 years after electrode implantation in ET patients despite possible tremor progression or stimulation tolerance. Although dysarthria and gait imbalance were commonly observed, particularly with bilateral DBS, most patients obtained satisfactory tremor control, but programming adjustments and DBS-related surgical procedures (about every 4 years) are needed to maintain clinically meaningful, long-term benefits.

Contributors JFB-C—research project: conception, organisation and execution; statistical analysis: design and execution; manuscript: writing of the first draft and review and critique. MNK—research project: organisation and execution, statistical analysis: review and critique; manuscript: review and critique. JJ-S—research project: organisation and execution, manuscript: review and critique. RF-research project: execution, manuscript: review and critique. JJ-research project: conception and organisation, statistical analysis: review and critique, manuscript: review and critique.

Competing interests JFBC: Honoraria from Medlink, Inc. Research support: Medtronic and Merz Pharmaceuticals. MNK: none. JJ-S: research support: Acadia, Siena, Neurosearch Sweden, Phytopharm, Schering-Plough, Avid Radiopharmaceutical. Speaking engagement and/or consulting: Medtronic, Teva, Lundbeck. RF: received honoraria from Medlink, Inc. and served as consultant for Lundbeck, LLC. and Teva Neuroscience, Inc. JJ: research support: Allergan, Inc; Allon Therapeutics; Biotie; Ceregene, Inc; Chelsea Therapeutics; Diana Helis Henry Medical Research Foundation; EMD Serono; Huntington's Disease Society of America; Huntington Study Group; Impax Pharmaceuticals; Ipsen Limited; Lundbeck Inc; Medtronic; Merz Pharmaceuticals; Michael J Fox Foundation for Parkinson Research; National Institutes of Health; National Parkinson Foundation; Neurogen; St. Jude Medical; Teva Pharmaceutical Industries Ltd; University of Rochester; Parkinson Study Group. Consultant or Advisory Committee Member: Allergan, Inc; AstraZeneca, Chelsea Therapeutics; EMD Serono; Lundbeck Inc; Merz Pharmaceuticals; Michael J Fox Foundation for Parkinson Research; Neurocrine Biosciences, Inc; Teva Pharmaceutical Industries Ltd. Editorial Boards: Elsevier; Medlink: Neurology; Neurology in Clinical Practice; Neurotoxin Institute; Scientiae; UpToDate.

Patient consent Obtained.

Ethics approval Baylor College of Medicine Institutional Review Board.

Provenance and peer review Not commissioned; externally peer reviewed. 


\section{REFERENCES}

1 Louis ED, Ferreira JJ. How common is the most common adult movement disorder? Update on the worldwide prevalence of essential tremor. Mov Disord 2010;25:534-41.

2 Lorenz D, Poremba C, Papengut F, et al. The psychosocial burden of essential tremor in an outpatient and a population based cohort. Eur J Neurol 2011;18:972-9.

3 Louis ED. Clinical practice. Essential Tremor. N Engl J Med 2001;345:887-91.

4 Flora ED, Perera CL, Cameron AL, et al. Deep brain stimulation for essential tremor: a systematic review. Mov Disord 2010:25:1550-9.

5 Baizabal-Carvallo JF, Simpson R, Jankovic J. Diagnosis and treatment of complications related to deep brain stimulation hardware. Mov Disord 2011;26:1398-406.

6 Sydow O, Thobois S, Aslesch F, et al. Multicentre European study of thalamic stimulation in essential tremor. A six year follow-up. J Neurol Neurosurg Psychiatry 2003;74:1387-91.

7 Rehncrona $\mathrm{S}$, Johnels $\mathrm{B}$, Widner $\mathrm{H}$, et al. Long-term efficacy of thalamic deep brain stimulation for tremor: double-blind assessments. Mov Disord 2003;18:163-70.

8 Zhang $\mathrm{K}$, Bhatia S, Oh MY, et al. Long-term results of thalamic deep brain stimulation for essential tremor. J Neurosurg 2010;112:1271-6.

9 Pahwa R, Lyons KE, Wilkinson SB, et al. Long-term evaluation of deep brain stimulation of the thalamus. J Neurosurg 2006;104:506-12.

10 Fahn S, Tolosa E, Marin C. Clinical ratings scale for tremor. In: Jankovic J, Tolosa E eds. Parkinson's disease and movement disorders. Baltimore, MD: Williams \& Wilkins, 1993:671-80.

11 Savica R, Matsumoto JY, Josephs KA, et al. Deep brain stimulation for benign tremulous parkinsonism. Arch Neurol 2011;68:1033-6.

12 Kenney C, Simpson R, Hunter C, et al. Short-term and long-term safety of deep brain stimulation in the treatment of movement disorders. J Neurosurg 2007:106:621-5
13 Baizabal-Carvallo JF, Mostile G, Almaguer M, et al. Deep brain stimulation hardware complications in patients with movement disorders: risk factors and clinical correlations. Stereotact Funct Neurosurg 2012:90:300-6.

14 Deuschl G, Raethjen J, Hellriegel $H$, et al. Treatment of patients with essential tremor. Lancet Neurol 2011;10:148-61.

15 Blomstedt P, Hariz GM, Hariz Ml, et al. Thalamic deep brain stimulation in the treatment of essential tremor: a long-term follow-up. $\mathrm{Br} J$ Neurosurg 2007;21:504-9.

16 Hariz GM, Blomstedt P, Koskinen LO. Long-term effect of deep brain stimulation for essential tremor on activities of daily living and health-related quality of life. Acta Neurol Scand 2008;118:387-94.

17 Lyons KE, Pahwa R, Busenbark KL, et al. Improvements in daily functioning after deep brain stimulation of the thalamus for intractable tremor. Mov Disord 1998;13:690-2.

18 Favilla CG, Ullman D, Wagle Shukla A, et al. Worsening essential tremor following deep brain stimulation: disease progression versus tolerance. Brain 2012;135:1455-62.

19 Boockvar JA, Telfeian A, Baltuch GH, et al. Long-term deep brain stimulation in a patient with essential tremor: clinical response and postmortem correlation with stimulator termination sites in ventral thalamus. Case report. $J$ Neurosurg 2000;93:140-4.

20 DiLorenzo DJ, Jankovic J, Simpson RK, et al. Long-term deep brain stimulation for essential tremor: 12-year clinicopathologic follow-up. Mov Disord 2010;25:232-8

21 Plaha P, Javed S, Agombar D, et al. Bilateral caudal zona incerta nucleus stimulation for essential tremor; outcome and quality of life. J Neurol Neurosurg Psychiatry 2011;82:899-904.

22 Fytagoridis A, Sandvik U, Aström M, et al. Long term follow-up of deep brain stimulation of the caudal zona incerta for essential tremor. J Neurol Neurosurg Psychiatry 2012:83:258-62. 